\title{
Redução de perdas no processo produtivo através da eliminação de bujão tecnológico no processo de usinagem da caixa de câmbio
}

\author{
Carlos Henrique, Flavio Goulart, Paulo Martins, Daniel Miranda, Paulo Paiva

\section{Grupo Fiat Chrysler} \\ E-mail: carloshenrique.silva@fcagroup.com,daniel.miranda@fcagroup.com, \\ flavio.goulart@fcagroup.com, paulosergio.martins@fcagroup.com, \\ paulo.carvalho@fcagroup.com
}

\begin{abstract}
O Brasil apresenta-se hoje como um grande mercado para a indústria automobilística, atraindo montadoras de todo o mundo. Esta abertura de mercado gera também uma redistribuição do espaço que cada montadora possui no país. E o caminho para se manter competitivo neste mercado promissor passa por otimizar os processos de produção. Este projeto foi desenvolvido em uma área produtiva de uma indústria automobilística visando reduzir custos no processo de fabricação de transmissões.
\end{abstract}

\section{INTRODUÇÃO}

Iniciativas para redução de custos têm sido implantadas em todo o mundo com o objetivo de otimizar os processos produtivos, tornando as empresa mais competitivas dia após dia. A Fiat Chrysler Powertrain, fabricante de conjuntos motopropulsores, não foge a esta regra e busca continuamente identificar potenciais de melhoria em seus processos, disponibilizando no mercado um produto que agrade em desempenho e custo.

Esta intenção fica evidente quando a fábrica define como diretriz de trabalho o conceito de World Class Manufacturing (WCM), ou Manufatura de Classe Mundial.

Assim, o objetivo deste de trabalho é descrever a aplicação de um método de análise e solução de problemas na redução de perdas. Especificamente busca-se identificar, priorizar e eliminar atividades que não agregam valor dentro do processo produtivo e demonstrar o resultado da correta aplicação do método de pesquisa. 


\section{METODOLOGIA DE PROJETO}

Baseado na metodologia de análise e solução de problemas dividida em 7 passos conforme descrito abaixo.

1. Definir o projeto;

2. Definir claramente o problema;

3. Estudar detalhadamente o problema;

4. Analisar a causa raiz;

5. Ações e contramedidas;

6. Resultados;

7. Padronizar as ações.

\section{Definição do Projeto}

O projeto foi definido a partir da análise das perdas existentes no processo produtivo. Estas perdas, após coletas no período de um ano foram tabuladas e dispostas no gráfico abaixo, denominado Cost Deployment.

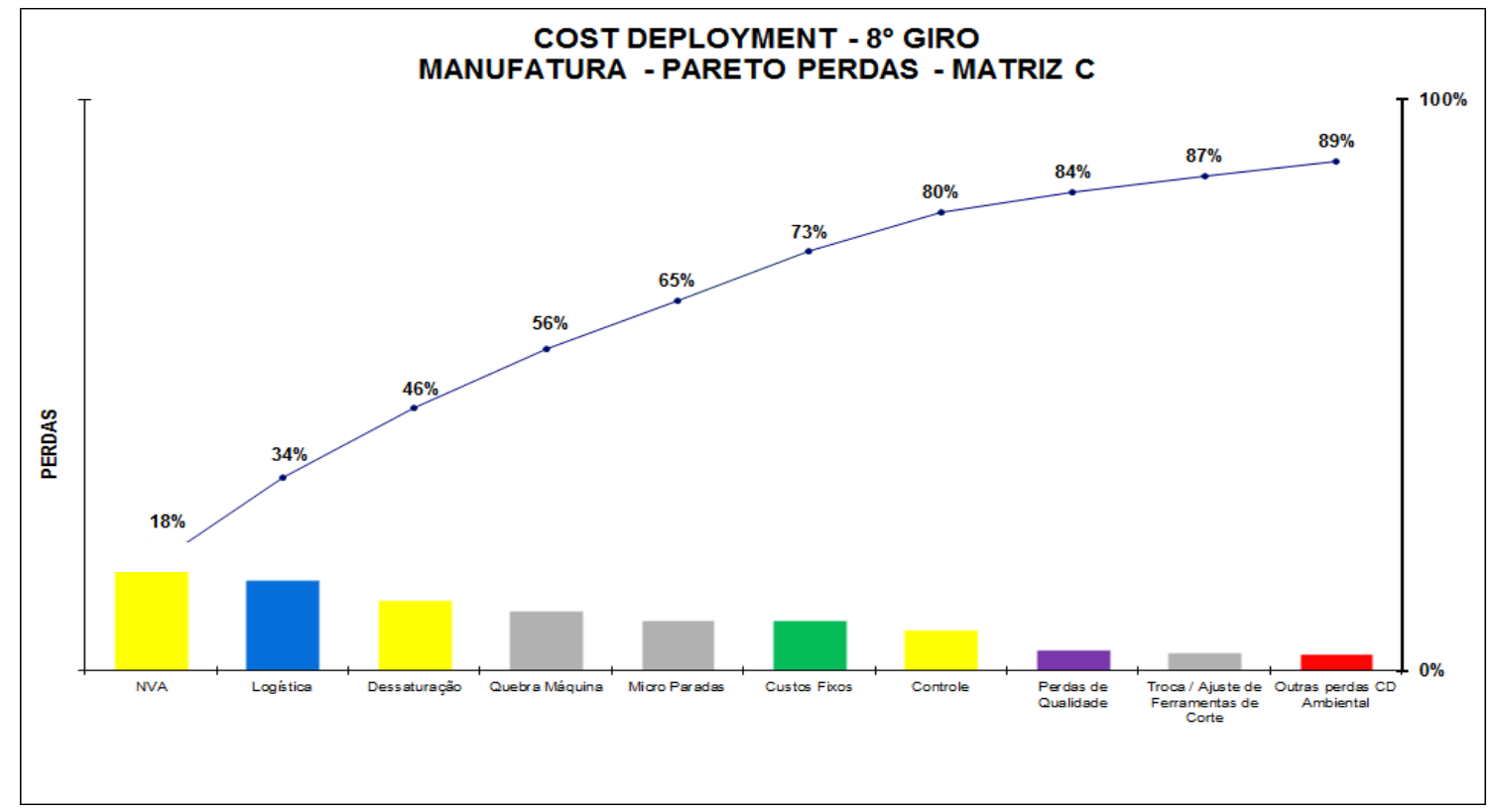

Gráfico 1: Pareto de perdas

A perda por NVA (atividade sem valor agregado) aparece em destaque no gráfico, mostrando onde devemos trabalhar. A prioridade neste caso é dada pelo valor acumulado de perda no ano. 
Sabendo que o NVA é a pior perda da fábrica, partimos então para o desenvolvimento de projetos que reduzissem esta perda na unidade de negócios. Percebemos neste primeiro passo que a fábrica utiliza a coleta e análise de suas perdas para direcionar os recursos humanos e financeiros no desenvolvimento de projetos.

Desta forma, portanto, passamos então a analisar em nossa unidade de negócio onde estariam nossas maiores perdas por NVA. Partimos para a estratificação do Cost Deployment por operação desta unidade e obtivemos o seguinte gráfico:

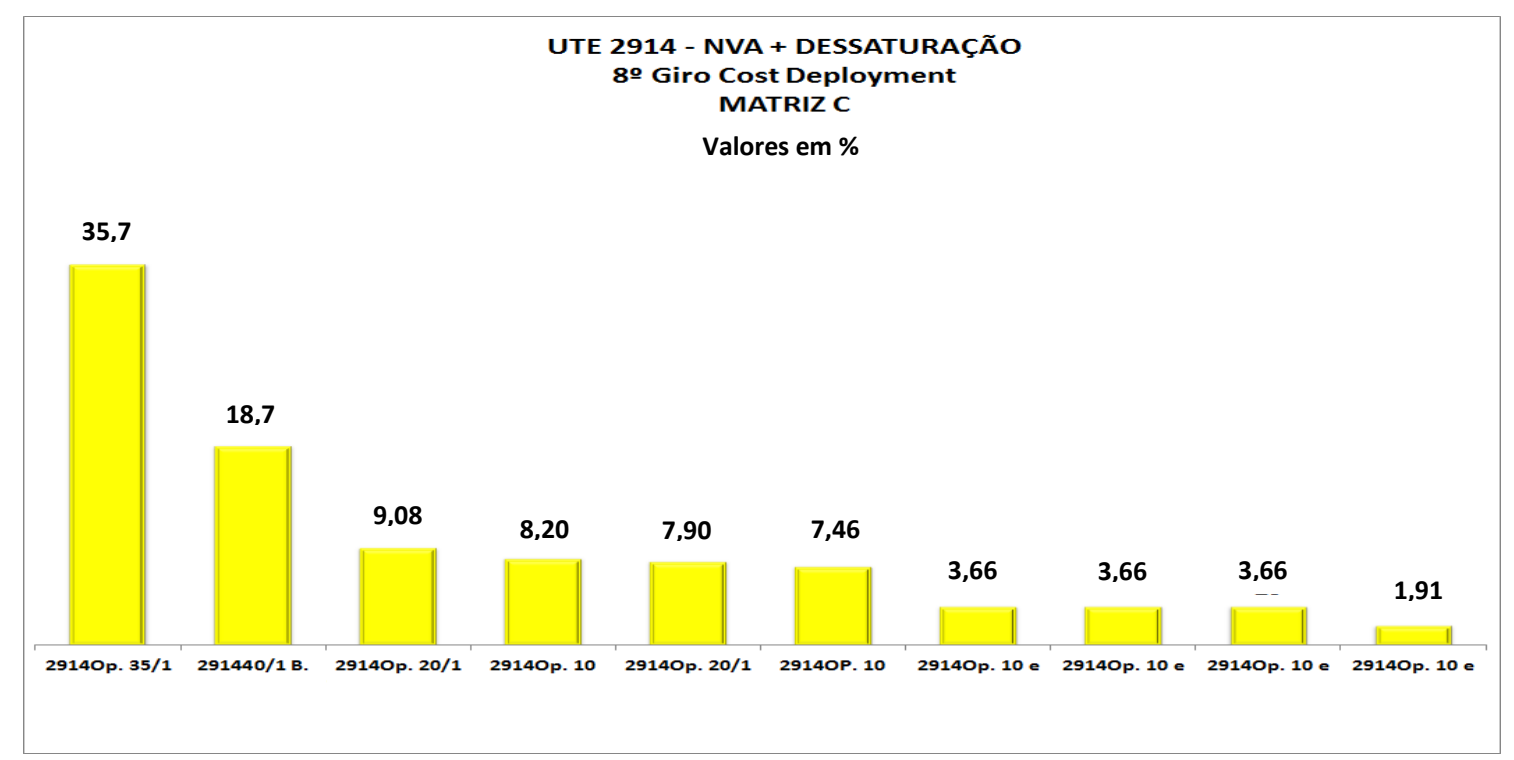

Gráfico 2: Estratificação de perdas por NVA na UTE 2914

Observa-se que a perda mais relevante na unidade de negócio está localizada na operação 35, denominada aqui como Lavadora Industrial.

\section{Definir claramente o problema}

Para entendermos melhor, segue abaixo um esboço do lay-out da UTE 2914:

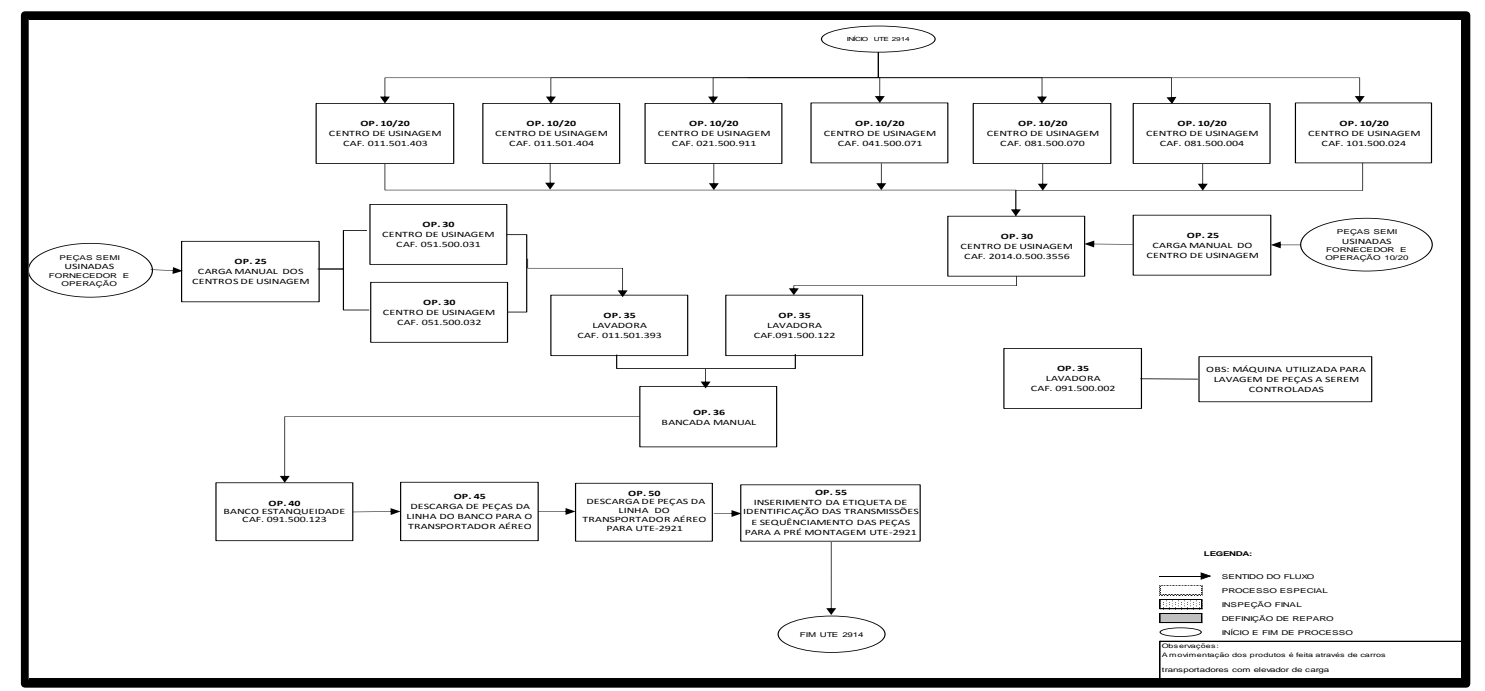

Figura 1: Lay-out do processo da UTE 2914 
O processo em destaque possui 4 postos de trabalho que funcionam em três turnos ininterruptos de produção, ou seja, existe a necessidade de 12 pessoas por dia para manter o funcionamento da operação. Nesta operação realiza-se as seguintes atividades:

- Lavadora Industrial: equipamento responsável pela limpeza e rebarbagem das peças provenientes da usinagem. São posicionados dois colaboradores sendo que um realiza a retirada de alarmes e colocação em funcionamento do equipamento, e o outro realiza a atividade de montagem do bujão de vedação da sede da haste de $1^{\mathrm{a}} / 2^{\mathrm{a}}$ velocidades;

- Teste de estanqueidade: equipamento responsável pelo teste de estanqueidade das peças (vazamento). É posicionado um colaborador para esta atividade;

- Segunda montagem de bujões: posiciona-se outro colaborador para a montagem dos bujões de vedação do ponto de escoamento de óleo e do ponto de abastecimento de óleo.

\section{Estudando detalhadamente o problema}

Sabendo que a lavadora Industrial representa nossa operação com maior perda dentro do processo produtivo, partimos para a estratificação das atividades realizadas nesta parte de processo.

Para começarmos a entender as perdas fizemos a filmagem deste ponto de processo e depois tabulamos em uma planilha eletrônica. Esta planilha contém as seguintes informações:

- Atividade: descreve pontualmente qual a atividade o operador realiza;

- Começo: início de contagem do relógio em minutos;

- Duração: tempo gasto em minutos para a realização da atividade;

- Fim: fim parcial de contagem do relógio em minutos;

- V/NV/R: a sigla V caracteriza a atividade como Valor Agregado; a sigla N caracteriza a atividade como Sem Valor Agregado; a sigla $\mathrm{R}$ caracteriza a atividade com Semi Valor Agregado (misto entre $\mathrm{V}$ e N);

- Freq: Frequência de realização da atividade;

- Dur/Freq: relação entre duração e frequência;

- Voz da Matriz D: caracterização de acordo com a voz de perda tabulada na Matriz de Custos;

- OP: quando a atividade é realizada pelo operador; 
- CPA: quando a atividade é realizada pelo Condutor de Processo Automatizado.

\begin{tabular}{|c|c|c|c|c|c|c|c|c|c|}
\hline Atividade & | Começo & | Duração & Fim & $\mathrm{v} / \mathrm{NV} / \mathrm{R}$ & Freq. & Dur/Freq & Voz da Matriz D & OP & CPA \\
\hline 1 Pega Suporte e posiciona na mesa & 0 & 2,756 & 2,756 & $R$ & 1 & 2,76 & NVA Aspectos Ergonomicos / LOPT & $\mathrm{x}$ & \\
\hline 2 Pega caixa & 2,756 & 0,479 & 3,235 & $R$ & 1 & 0,48 & NVA Aspectos Ergonomicos / LOPT & $\mathrm{x}$ & \\
\hline 3 Caminha & 3,235 & 1,049 & 4,284 & $\mathrm{~N}$ & 1 & 1,05 & NVA Aspectos Logisticos & $\mathrm{x}$ & \\
\hline 4 Posiciona caixa na mesa de aperto do bujao & 4,284 & 1,678 & 5,962 & $\mathrm{~N}$ & 1 & 1,68 & NVA Aspectos Ergonomicos / LOPT & $\mathrm{x}$ & \\
\hline 5 Pega chave & 5,962 & 0,719 & 6,681 & $R$ & 1 & 0,72 & NVA Aspectos Ergonomicos / LOPT & $\mathrm{x}$ & \\
\hline 6 Pega bujao & 6,681 & 1,198 & 7,879 & $R$ & 1 & 1,20 & NVA Aspectos Ergonomicos / LOPT & $\mathrm{x}$ & \\
\hline 7 Passa loctite & 7,879 & 1,228 & 9,107 & $\mathrm{~V}$ & 1 & 1,23 & & $\mathrm{x}$ & \\
\hline 8 Posiciona bujao na caixa & 9,107 & 2,277 & 11,384 & $\mathrm{~N}$ & 1 & 2,28 & NVA Aspectos Ergonomicos / LOPT & $\mathrm{x}$ & \\
\hline 9 Pega apertadeira & 11,384 & 2,996 & 14,38 & $R$ & 1 & 3,00 & NVA Aspectos Ergonomicos / LOPT & $\mathrm{x}$ & \\
\hline 10 Aperta bujao & 14,38 & 2,936 & 17,316 & & 1 & 2,94 & & $\mathrm{x}$ & \\
\hline 11 Guarda apertadeira & 17,316 & 1,438 & 18,754 & & 1 & 1,44 & NVA Aspectos Ergonomicos / LOPT & $\mathrm{x}$ & \\
\hline 12 Pega pistola de ar comprimido & 18,754 & 0,24 & 18,994 & & 1 & 0,24 & NVA Aspectos Ergonomicos / LOPT & $\mathrm{x}$ & \\
\hline 13 Assopra peca & 18,994 & 1,408 & 20,402 & $\mathrm{~N}$ & 1 & 1,41 & NVA Aspectos Ergonomicos / LOPT & $\mathrm{x}$ & \\
\hline 14 Guarda pistola de ar comprimido & 20,402 & 0,629 & 21,031 & & 1 & 0,63 & NVA Aspectos Ergonomicos / LOPT & $\mathrm{x}$ & \\
\hline 15 Pega caixa & 21,031 & 0,899 & 21,93 & & 1 & 0,90 & NVA Aspectos Ergonomicos / LOPT & $\mathrm{x}$ & \\
\hline 16 Caminha & 21,93 & 0,839 & 22,769 & & 1 & 0,84 & NVA Aspectos Logisticos & $\mathrm{x}$ & \\
\hline 17 Coloca caixa sobre a mesa & 22,769 & 1,258 & 24,027 & & 1 & 1,26 & NVA Aspectos Ergonomicos / LOPT & $\mathrm{x}$ & \\
\hline 18 Caminha & 24,027 & 1,109 & 25,136 & & 1 & 1,11 & NVA Aspectos Logisticos & $\mathrm{x}$ & \\
\hline 19 Espera & 25,136 & 1,738 & 26,874 & & 1 & 1,74 & NVA Espera & $\mathrm{x}$ & \\
\hline
\end{tabular}

Tabela 1: Análise de tempos na operação da Lavadora Industrial

A partir da tabulação destas informações, formatamos o gráfico abaixo que nos mostra a distribuição percentual das atividades, caracterizadas por sua natureza.

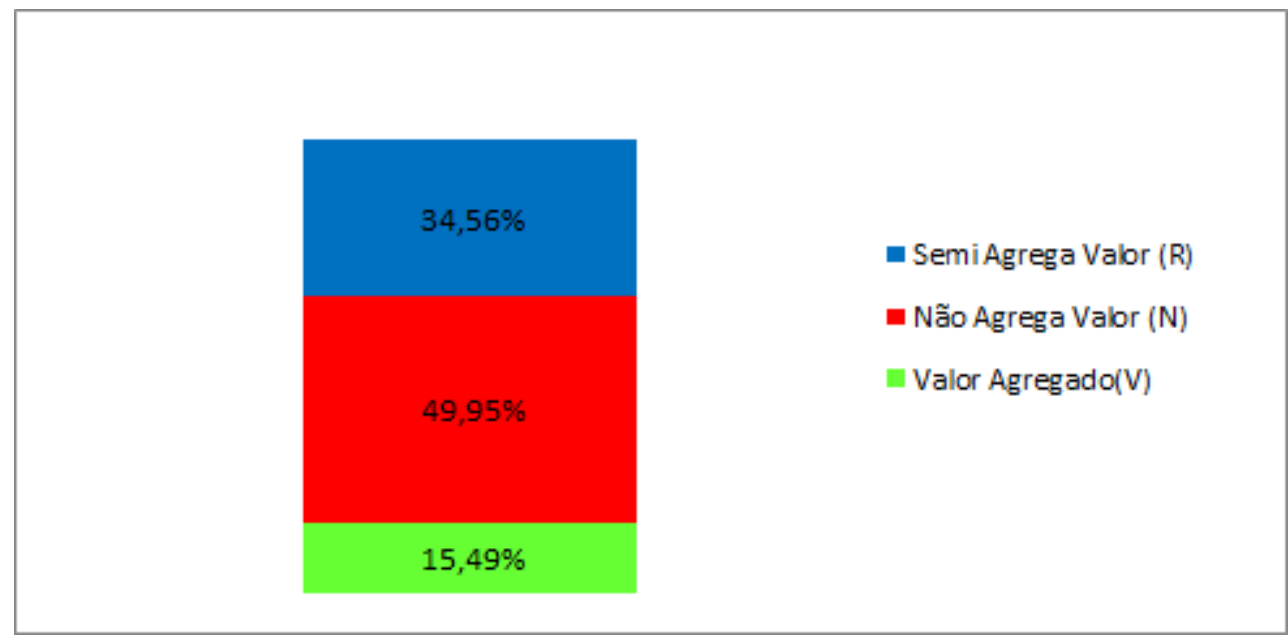

Gráfico 3: Percentuais de perdas conforme classificação

Com foco nas atividades que não agregam valor, sinalizadas no gráfico acima pela fatia do meio (49,95\%), aprofundamos as análises conforme planilha abaixo: 


\begin{tabular}{|l|c|c|c|c|c|c|}
\hline \multicolumn{1}{|c|}{ Atividade } & Começo & Duração & Fim & VINV/R & Freq. & \multicolumn{1}{|c|}{ Dur/Freq } \\
\hline 3 Caminha & $\mathbf{3 , 2 3 5}$ & $\mathbf{1 , 0 4 9}$ & $\mathbf{4 , 2 8 4}$ & $\mathbf{N}$ & $\mathbf{1}$ & $\mathbf{1 , 0 5}$ \\
\hline 4 Posiciona caixa na mesa de aperto do bujao & $\mathbf{4 , 2 8 4}$ & $\mathbf{1 , 6 7 8}$ & $\mathbf{5 , 9 6 2}$ & $\mathbf{N}$ & $\mathbf{1}$ & $\mathbf{1 , 6 8}$ \\
\hline 8 Posiciona bujao na caixa & $\mathbf{9 , 1 0 7}$ & $\mathbf{2 , 2 7 7}$ & $\mathbf{1 1 , 3 8 4}$ & $\mathbf{N}$ & $\mathbf{1}$ & $\mathbf{2 , 2 8}$ \\
\hline 11 Guarda apertadeira & $\mathbf{1 7 , 3 1 6}$ & $\mathbf{1 , 4 3 8}$ & $\mathbf{1 8 , 7 5 4}$ & $\mathbf{N}$ & $\mathbf{1}$ & $\mathbf{1 , 4 4}$ \\
\hline 13 Assopra peca & 18,994 & 1,408 & 20,402 & $\mathrm{~N}$ & 1 & 1,41 \\
\hline 14 Guarda pistola de ar comprimido & 20,402 & 0,629 & 21,031 & $\mathrm{~N}$ & 1 & 0 \\
\hline 16 Caminha & 21,93 & 0,839 & 22,769 & $\mathrm{~N}$ & 1 & 0,84 \\
\hline 17 Coloca caixa sobre a mesa & 22,769 & 1,258 & 24,027 & $\mathrm{~N}$ & 1 & 1,26 \\
\hline 18 Caminha & 24,027 & 1,109 & 25,136 & $\mathrm{~N}$ & 1 & 1,11 \\
\hline 19 Espera & 25,136 & 1,738 & 26,874 & $\mathrm{~N}$ & 1 & 1,74 \\
\hline
\end{tabular}

Tabela 2: Análise de tempos para a atividade de montagem do bujão

Percebe-se que as quatro atividades iniciais, que representam o conjunto de atividades realizadas para a montagem do bujão de vedação das hastes de $1^{\mathrm{a}} / 2^{\mathrm{a}}$ velocidades, contribui com 47,98\% das perdas por NVA na Lavadora Industrial.

A partir deste ponto, conforme demonstrado nos dados acima, começamos a estudar melhor a atividade de desbaste e acabamento da furação para sede da haste de $1^{\mathrm{a}} / 2^{\mathrm{a}}$ velocidades, assim como a atividade de montagem do bujão para vedação desta furação.

\subsection{Estudando o processo de produção}

$\underline{\text { A Caixa de Câmbio e o bujão de vedação da sede da haste } 1^{\mathrm{a}} / 2^{\mathrm{a}} \text { velocidades }}$

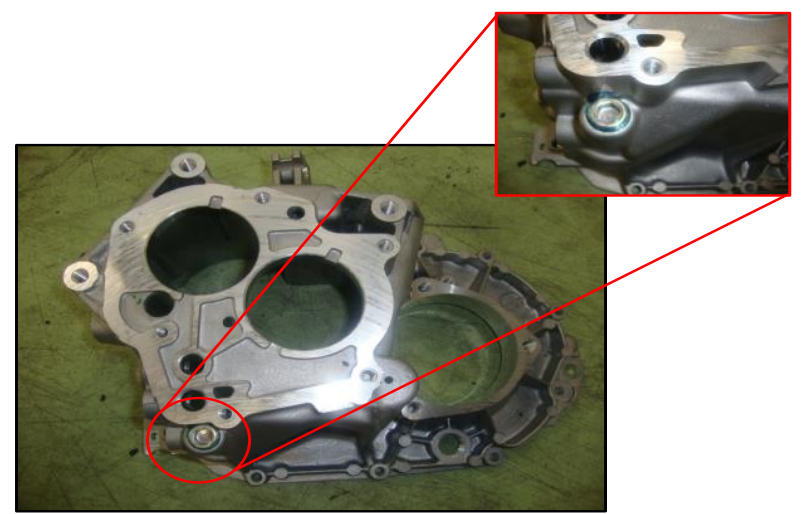

Figura 2: Detalhe caixa de câmbio e bujão de vedação

A caixa de câmbio é uma peça fabricada em liga de alumínio e recebe todos os outros componentes internos e periféricos que formam a transmissão de um veículo. 


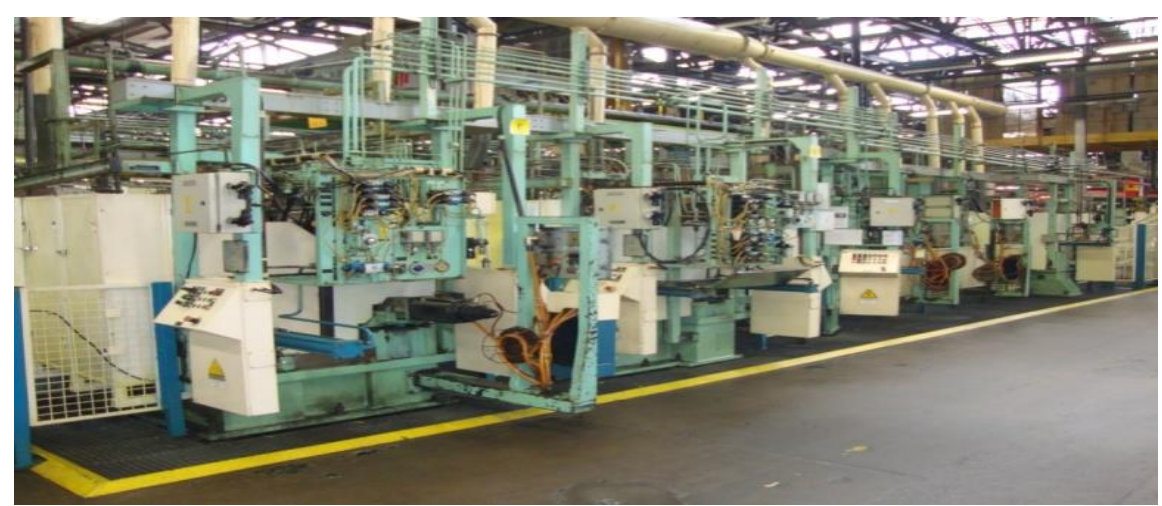

Figura 3: Transferta

As Transfertas são máquinas operatrizes rígidas, constituídas por várias estações de trabalho, providas com dispositivos e ferramentas com uma função específica.

\section{$\underline{\text { O processo - fluxo de usinagem }}$}

No processo atual, a usinagem da sede do bujão da $1^{\mathrm{a}} / 2^{\mathrm{a}}$ velocidades é realizada conforme o fluxo a seguir:

1 Furação na Transferta 562: é utilizada uma broca de aço rápido com Ø12,5mm;

2 Furação na Transferta 562: é utilizado um alargador de aço rápido com $\varnothing 18 \mathrm{~mm}$ para preparação do rosqueamento;

3• Rosqueamento na Transferta 562: é utilizado um macho M18x1,25;

4• Mandrilhamento na Transferta 563: é utilizada uma barra de mandrilar $\varnothing 13,5 \mathrm{~mm}$ para preparação da usinagem de acabamento do furo;

5- Mandrilhamento no Centro de Usinagem operação 30: é utilizada uma barra de mandrilar para acabamento da sede da haste de comando da $1^{\mathrm{a}} / 2^{\mathrm{a}}$ velocidades.

6• Limpeza e rebarbagem da peça: operação realizada pela Lavadora Industrial;

7• Montagem manual do bujão $1^{\mathrm{a}} / 2^{\mathrm{a}}$ velocidade: o colaborador monta manualmente o bujão na caixa de câmbio e utiliza uma apertadeira elétrica para aplicar o torque adequado na montagem. 


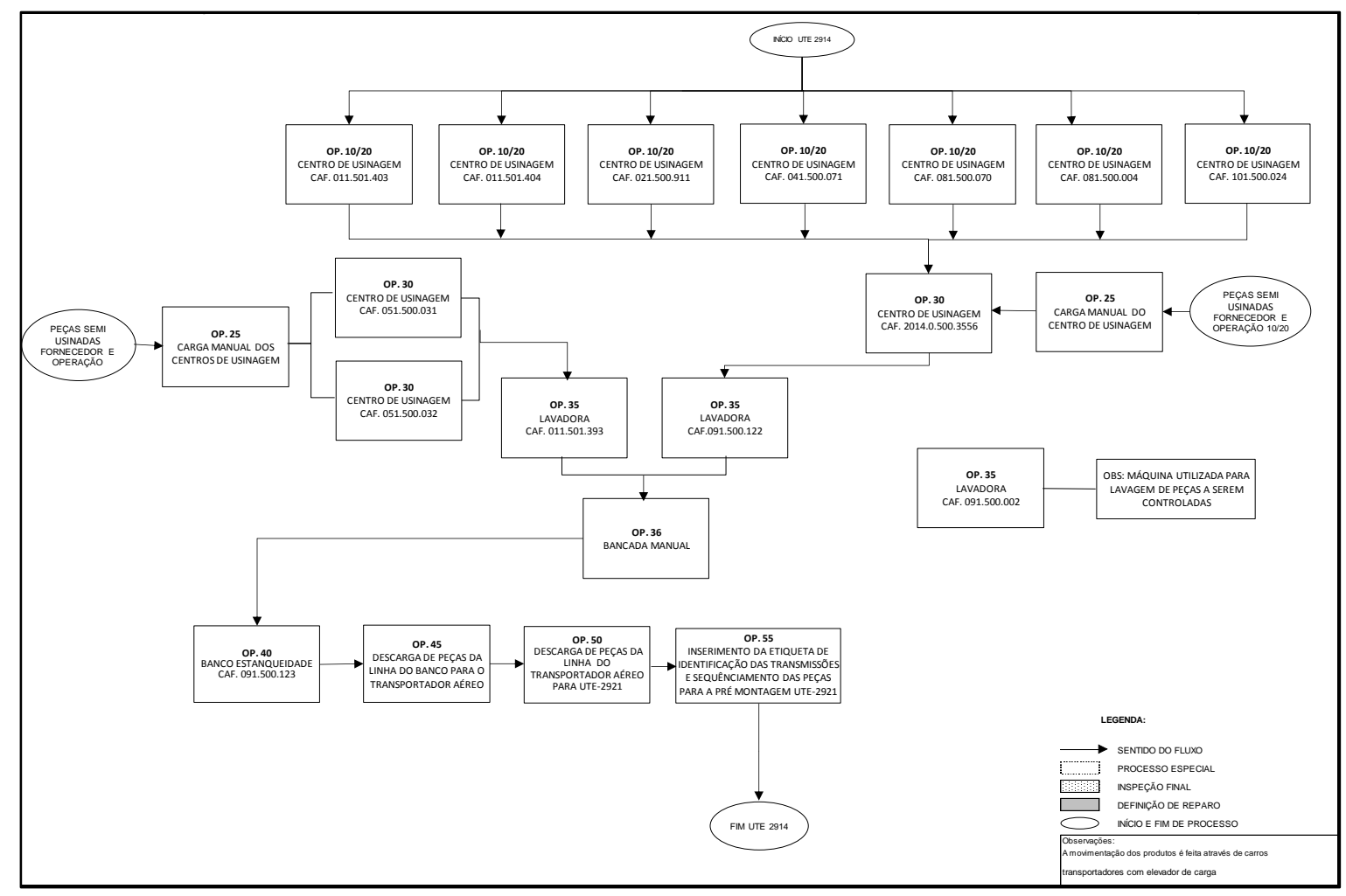

Figura 4: Fluxo de produção da caixa de câmbio

\section{Buscando a Causa Raiz deste problema}

Este fluxo de usinagem foi desenvolvido há 20 anos, sendo que o processo passou por várias modificações e atualizações tecnológicas que nos possibilitaram discutir maneiras mais eficientes de produzir.

Uma destas atualizações tecnológicas foi a aquisição de novos centros de usinagem para acabamento de nossas peças. Esta máquinas estão identificadas no esquema acima como centros de usinagem operação 30. Antes da aquisição destes dois centros de usinagem, o acabamento era feito em outra Transferta que, como sabemos, são máquinas rígidas que não permitem grandes alterações ou melhorias.

No processo anterior, onde o acabamento era realizado por uma Transferta posicionada após a Transferta 563, era necessária a realização de uma furação por onde passaria uma barra de mandrilar para acabamento do furo sede da haste de $1 \frac{\mathrm{a}}{2^{\mathrm{a}}}$ velocidades. Esta furação, portanto, deveria ser vedada após o acabamento da peça. 


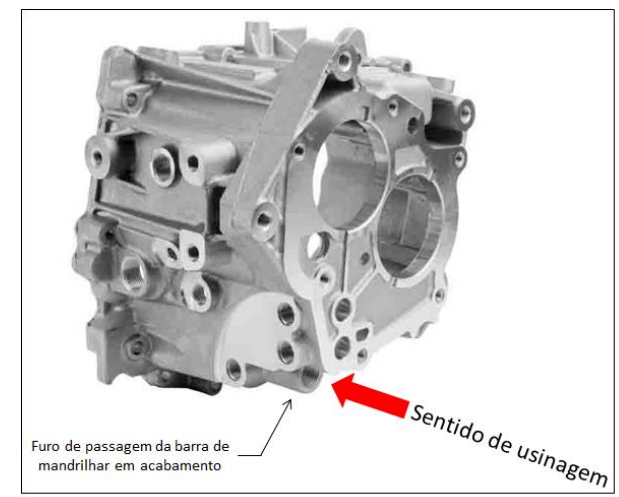

Figura 5: Sentido de usinagem do acabamento do diâmetro sede da haste

Identificamos que a causa da perda existente na operação de lavagem da caixa de câmbio ocorria devido a execução de uma furação de preparação para posterior passagem de uma barra de mandrilar que usinaria em acabamento a sede da haste.

\section{Definindo ações e contramedidas}

A partir de agora dedicaremos tempo ao levantamento e análise das soluções para eliminação da causa identificada anteriormente.

Com a aquisição de novas máquinas para substituição da antiga Transferta de acabamento, que como sabemos era uma máquina rígida, criou-se a oportunidade de inversão da usinagem de acabamento da sede da haste da $1^{\mathrm{a}} / 2^{\mathrm{a}}$ velocidades. Ou seja, a barra de mandrilar responsável por este acabamento poderia realizar sua função pela parte contrária a realizada anteriormente, eliminando a necessidade da furação de passagem realizada antes. Para exemplificar essa ideia, segue um desenho esquemático da melhoria proposta.

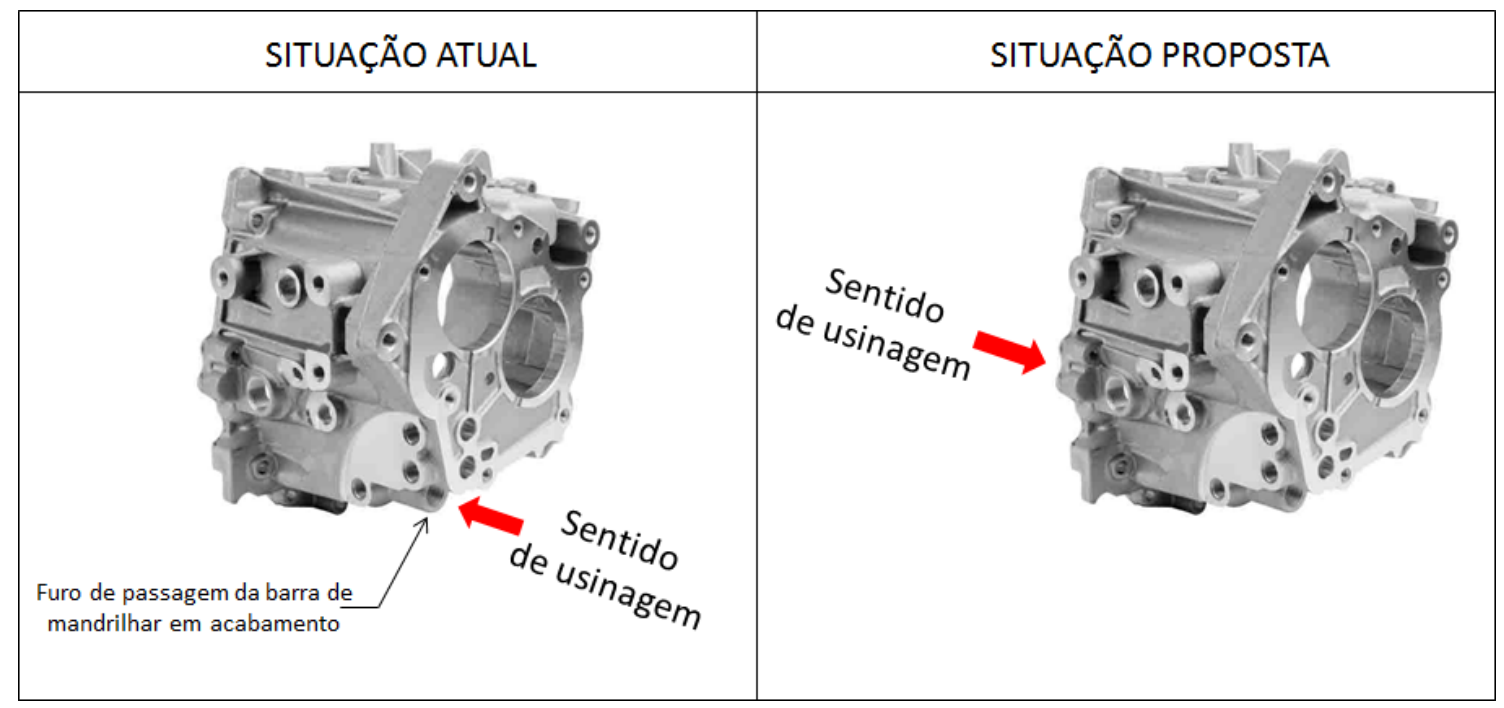

Figura 6: Detalhe da modificação proposta 
Ao mudar o sentido da entrada da ferramenta de acabamento (barra de mandrilar), eliminamos na necessidade de execução do furo de passagem.

\section{Resultados}

Após as modificações implantadas no processo de usinagem, tivemos os seguintes ganhos:

- eliminação de um desenho da lista básica de produção (bujão de vedação);

• eliminação de perda com mão-de-obra de 3080 horas/ano;

- redução do consumo de $10 \mathrm{~kg}$ de adesivo de vedação por ano;

- redução do consumo de 6 brocas utilizadas na furação por ano;

- redução do consumo de 10 machos rosqueadores por ano;

- redução do consumo de 40 insertos utilizados no pré-acabamento por ano;

- eliminação de uma apertadeira elétrica e controlador de torque automático.

\begin{tabular}{|l|c|}
\hline \multicolumn{1}{|c|}{ ÍTEM } & $\begin{array}{c}\text { CONSUMO } \\
\text { ANUAL }\end{array}$ \\
\hline Bujão & 687480 \\
\hline $\begin{array}{l}\text { Mão de obra op.36 } \\
220 \mathrm{hs} \mathrm{X} 17,42 \times 14 \\
\text { meses }\end{array}$ & $3080 \mathrm{hs}$ \\
\hline Adesivo de Vedação & $10 \mathrm{Kg}$ \\
\hline Broca & 6 \\
\hline Macho & 10 \\
\hline Inserto & 40 \\
\hline Barra & 2 \\
\hline Power focus & 1 \\
\hline Apertadeira & 1 \\
\hline
\end{tabular}

Custo de Implantação: $\mathbf{R} \$ 1.250,00$

REDUÇ̃̃O ANUAL ESTIMADO:

R\$ 305894,68/ano

Tabela 3: Ganhos estimados após melhoria

\section{Padronização}

Como forma de garantir que o conhecimento adquirido ficará disponível para o futuro da empresa, foram atualizados os documentos de processo que definem o fluxo de trabalho, os recursos a serem empregados e os tempos previstos para produção. 


\section{Conclusão}

Retornando ao objetivo inicial proposto pelo projeto, que era reduzir perdas com atividades sem valor agregado, através da utilização de um método de análise e solução de problemas, podemos concluir que o objetivo foi alcançado. Demonstra-se que, a partir da utilização de um método de trabalho, os resultados ficam mais claros, as causas bem definidas, o conhecimento fica assegurado através do registro, possibilitando sua expansão para outros setores da fábrica.

\section{Referências}

Guia dos Pilares Técnicos da Fiat Chrysler Latam

YAMASHINA, Hajime: Just-in-time Production - A New Formulation and Algorithm of the Flow Shop Problem. Computer - Aided Production Management - 1988

\section{ABREVIAÇÕES}

WCM: World Class Manufacturing

NVA: Not Value Added (Sem Valor Agragado)

UTE: Unidade Tecnológica Elementar;

EM: Engenharia de Manufatura 